\title{
New evidence on the effect of smoking on the obesity risk among adults, Findings from the China Health and Nutrition Survey (CHNS, 1991-2015)
}

\author{
Jian Zhao ( $\square$ zhaojian@ibms.pumc.edu.cn ) \\ Chinese Academy of Medical Sciences and Peking Union Medical College Institute of Basic Medical Sciences \\ Jian Sun \\ Ningxia Medical University
}

\section{Research}

Keywords: Smoking, Obesity, physical activity, dietary intake, drinking

Posted Date: February 17th, 2020

DOI: https://doi.org/10.21203/rs.2.23668/v1

License: () (1) This work is licensed under a Creative Commons Attribution 4.0 International License. Read Full License 


\section{Abstract}

Background: To estimate the approximately causal effects of smoking on the obesity risk among Chinese adults.

Methods: Using China Health and Nutrition Survey (CHNS) datasets from 1991 to 2015, this study consisted of 35,907 males and 39,441females aged 18-65 years. Using ordinary-least squares and probit models to investigate the effects of smoking on risk of obesity among Chinese adults.

Results: Male current smokers had a higher dietary energy intake (23.28 unit), percentage of dietary energy intake from fat ( 0.47 unit), physical activity ( 9.96 unit), drinking ( 0.61 unit) but less likely to be general obesity ( 0.17 unit) and abdominal obesity ( 0.12 unit) than nonsmokers. Female current smokers less likely to be general obesity ( 0.03 unit) and abdominal obesity ( 0.12 unit) than nonsmokers. Male heavy smokers ( $>25$ cigarettes/d) had higher dietary energy intake (89.65 unit), physical activity (15.31 unit), drinking (0.08 unit) and more likely to be general obesity ( 0.18 unit) and abdominal obesity ( 0.10 unit) than other smokers.

Conclusions: Compared with nonsmokers, current smokers had lower probability of being general obesity and abdominal obesity among Chinese adults regardless of gender. Male heavy smokers increased the risk of obesity than other smokers. These findings may improve the understanding on how cigarette smoking affects fat distribution and provide scientific evidence regarding intervention in smoking and obesity, especially for male heavy smokers

\section{Introduction}

Smoking alone or in combination with obesity poses the major public health burden in western societies as well as many developing countries[1]. Generally, obesity epidemic is mostly attributed to behavioral risks, however, smoking may seriously influence individual risk of obesity as well. [2-4]. Understanding pathways that contribute to these risk factors, and the nature of the relationship between them, is therefore of paramount importance for disease prevention[5].

Existing evidences about the effects of smoking on obesity risks are complex and not yet completely understood [6, 7]. Numerous cross-sectional studies have reported that BMI are lower in current smokers than in nonsmokers while other studies have found a Ushaped relationship between smoking and BMI[8, 9].However, heavy smoking has been found to be associated with higher BMI[10]. Moreover, some studies have reported that current smokers have more abdominal obesity than never smokers[11-13],but other studies indicated no evidence for this association[14, 15]or have even found the opposite[16, 17]. There is a general perception that smoking decreases body weight due to reasons like decrease in appetite and calorie intake, enhanced metabolism, and reduced fat accumulation[18].However, despite their lower body weights, current smokers do not eat less than nonsmokers and tend to eat slightly more[19]. Evidences shows that smoking is associated with more physical activity due to specific occupational groups and activity types[20, 21],while smoking reduced activity is more commonly found[22]. These conflicting results may be because of data differences and model specifications[23]. More empirical evidences are needed to figure out the effects of smoking on obesity risk.

China is the world's largest consumer and manufacturer of tobacco, which is also experiencing a steady rise in obesity rates. Our objectives therefore were to evaluate, in a representative longitudinal study of Chinese adults, how smoking influenced the risk of obesity, how this was related to be general obesity and abdominal obesity, and whether these relationships varied by smoking intensity.

\section{Methods}

\section{Study Population and Data Collection}

Data from the China Health and Nutrition Survey (CHNS,1991-2015), which is a large-scale, longitudinal household-based survey initiated in 1989 that consists of representative participants of varying economic status, health indicators, and geographic areas throughout China[24]. Further information on survey procedures and the sampling scheme was reported in detail elsewhere [25]. We excluded participants who were pregnant, lactating, missing key variables from the analysis. Hence, our final sample consisted of 75,348 person-year observations aged 18-65 years with complete data on demographic, smoking status, obesity indicators.

\subsection{Obesity indicators}

Well-trained health workers measured the height, weight, and wasit circumstance (WC) following standardized procedures. Dividing weight (in $\mathrm{kg}$ ) by the square of height (in $\left.\mathrm{m}^{2}\right)$ we got BMl and grouped it into thin $\left(<18.5 \mathrm{~kg} / \mathrm{m}^{2}\right)$, normal $\left(18.5-23.9 \mathrm{~kg} / \mathrm{m}^{2}\right)$, overweight 
$\left(24-27.9 \mathrm{~kg} / \mathrm{m}^{2}\right)$ and obesity $\left(>28 \mathrm{~kg} / \mathrm{m}^{2}\right)$ [26]. We defined participants as having abdominal obesity if the WC $\geq 85 \mathrm{~cm}$ in females and $\geq 90 \mathrm{~cm}$ in males In accordance with the national health and family commission for Chinese adults (2013)[27].

\subsection{Smoking indicators}

In the CHNS questionnaire, two variables were constructed to measure smoking behavior. The first was smoking status, which was classified into "current smoker" or "nonsmoker". The second was smoking intensity, based on the question about "number of cigarettes consumed daily", current smokers were further divided into heavy ( 825 cigarette/d), moderate (15-24cigarette/d) and light smokers (114cigarette/d)[18].

\subsection{Other variables}

We grouped participants into three education level (primary/illiterate, middle, and high school/above), two marital statuses (single / married), two geographical regions (rural / urban), three income levels (low / medium / high) and two drinking status (yes/no). The percapital annual income in each survey was inflated to values in 2015. Participants reported all physical activities (PA) in average hours per week, and we converted the time spent in each activity into a metabolic equivalent of task (MET) hours per week based on the Compendium of Physical Activities [28].Dietary intake at the individual level was assessed by using three consecutive 24-h dietary recalls in each wave of the CHNS [24]. Based on the Chinese Food Composition Table, we measured nutrition intake data by (1) the respondent's daily calorie intake per day during a 3-day measurement period and (2) the dietary structure as indicated by the percentage of fat in the respondent's daily calorie intake [26].

\section{Statistical Analysis}

Statistical analyses were performed using the STATA 13.0 (STATA, Stata Corp). We first employed a pooled ordinary least square (OLS) model covering from1991 to 2015. Outcome variables including dietary energy intake, the percentage of dietary intake from fat and physical activity.

The equation we used for this model is

$\mathrm{K}_{\mathrm{abc}}=\mathrm{a}_{0}+\mathrm{a}_{1}$ SMOKE $_{\mathrm{abc}}+\mathrm{a}_{2} \mathrm{X}_{\mathrm{abc}}+\delta_{\mathrm{c}}+\mathrm{a}_{\mathrm{b}}+\varepsilon_{\mathrm{abc}}(1)$

$\mathrm{K}_{\mathrm{abc}}$ denote the lifestyle behavior of individual $\mathrm{a}$ in province $\mathrm{b}$ and year $\mathrm{c}$.

$\mathrm{SMOKE}_{\mathrm{abc}}$ indicating whether the individual is current smoker or nonsmoker in year c;

$\mathrm{X}_{\mathrm{abc}}$ contains control variables;

$\delta_{c}$ and $a_{b}$ indicate time and province fixed-effects, respectively;

$\varepsilon_{\mathrm{abc}}$ is the random error that varies with individual, province and year.

$\mathrm{a}_{1}$ indicates the impact of smoking on the lifestyle behavior.

Then we employed Probit model for binary dependent variables. Outcome variables including drinking status, general obesity and abdominal obesity. The equation we used for this model:

$\mathrm{K}_{\mathrm{abc}}^{\prime}=\mathrm{a}_{0}+\mathrm{a}_{1} \mathrm{SMOKE}_{\mathrm{abc}}+\mathrm{a}_{2} \mathrm{X}_{\mathrm{abc}}+\delta_{\mathrm{c}}+\mathrm{a}_{\mathrm{b}}+\varepsilon_{\mathrm{abc}}(2)$

$P=\left(K_{a b c}=\mid S M O K E, X, \delta, a\right)=P\left(K_{a b c}^{\prime}=\mid S M O K E, X, \delta, a\right)$

$=G\left(a_{1} S_{M O K E} a b c+a_{2} X_{a b c}+\delta_{c}+a_{b}+\varepsilon_{a b c}\right)(3)$

$\mathrm{K}^{\prime}{ }_{\mathrm{abc}}$ is the latent variable specifying the tendency of drinking, being general obesity and abdominal obesity. If $\mathrm{K}_{\mathrm{abc}}^{\prime}>0$, then $\mathrm{K}_{\mathrm{abc}}$ $=1$; Otherwise $\mathrm{K}_{\mathrm{abc}}=0$.

$\mathrm{G}($.$) is the cumulative distribution function of random error \varepsilon_{\mathrm{abc}}$. 
When we investigate the effects of smoking intensity on lifestyle behaviors. We change the SMOKE $\mathrm{abc}_{\text {in }}$ model $1-3$ to SMOKEI abc. $\mathrm{SMOKEI}_{\mathrm{abc}}$ is dummy variable indicating whether the current smoker is heavy smoker $(1=$ yes, $0=$ no), moderate smoker $(1=$ yes, $0=$ no) or light smoker ( $1=$ yes, $0=$ no).

\section{Results}

\section{Descriptive statistics}

Table 1 shows descriptive statistics for the variables by smoking status. Among the 75,348 participants, 22,541(29.90\%) were current smokers and $52,807(70.10 \%)$ were nonsmokers. Current smokers were about a year older on average than nonsmokers in our sample (43.58 vs. 42.72). The mean value of dietary energy intake was $2,280 \mathrm{kcal} / \mathrm{d}$, current smokers had higher dietary energy intake than nonsmokers $(2,480 \mathrm{kcal} / \mathrm{d}$ vs. $2,180 \mathrm{kcal} / \mathrm{d})(p<0.001)$. Nonsmokers consumed more percentage of energy intake from fat than current smokers $(30.30 \%$ vs. $29.70 \%)(p<0.001)$. The average rates of general obesity and abdominal obesity were significantly higher in nonsmokers than in smokers ( $8 \%$ vs. $6 \%$ and $41 \%$ vs. $35 \%$, respectively) $(p<0.001)$.

Table 2 shows the trends of characteristic of current smokers. From 1991 to 2015 , heavy smokers increased from $8 \%$ to $14 \%$ ( $p<$ $0.001)$. while light smokers decreased from $45 \%$ to $39 \%(p<0.001)$. Dietary energy intake of current smokers decreased from 2,890 $\mathrm{kcal}$ to $2,240 \mathrm{kcal}(p<0.001)$, while the percentage of energy intake from fat increased from $25.93 \%$ to $36.72 \%(p<0.001)$. It is noteworthy, the prevalence of overweight and obesity in current smokers increased significantly in mainland China from CHNS 1991 to $2015(p<0.001)$ (Figure 1).

\section{Effects of smoking behavior on risk of obesity among the whole population}

The OLS and Probit results were presented in Table 3 and Table 4, respectively. There was a significant correlation between smoking behavior and obesity risk. Male current smokers had higher dietary energy intake, percentage of energy intake from fat, physical activity and likelihood being drinking by 23.28 unit, 0.47 unit, 9.96 unit and 0.61 unit than nonsmokers, respectively. Female current smokers also had higher percentage of energy intake from fat and likelihood being drinking by 0.60 unit and 0.79 unit than female nonsmokers, respectively (Table 3).

After controlling for confounding factors, current smokers had a lower BMI and WC than nonsmokers regardless of gender. Smoking decreased the likelihood being general obesity by 0.17 unit in males and 0.03 unit in females, and abdominal obesity by 0.12 unit in males and females (Table 4).

\section{Marginal effects of smoking intensities among current smokers}

Figure 2 shows that the prevalence of general and abdominal obesity among smokers varies by smoking intensity among males and females. In addition, male had higher prevalence of general obesity and abdominal obesity than female across different smoking intensities. Male heavy smokers had more dietary energy intake by 89.65 unit, percentage of energy intake from fat by 15.31 unit, and more likelihood being drinking by 0.08 unit. While there were no differences among smoking intensities in female (Table 3). After controlling confounding factors, male moderate smokers had lower WC by 0.15 unit, BMI by 0.20 units, and less likely to be general obese by 0.05 unit than other smokers. Male heavy smokers had larger BMI by 0.22 unit, WC by 0.32 unit, increased the likelihood being general obesity by 0.18 units and abdominal obesity by 0.10 units than other smokers (Table 4 ).

\section{Discussion}

\section{Smoking and risk of obesity}

Using a representative cohort with more than 20-year follow-up, in summarize, it appears that male current smokers declared higher intakes of dietary energy, fat and alcohol than male nonsmokers, contradicting their significantly lower body weight outcomes in this research. This result is consistent with the results of a meta-analysis from 15 developed countries[29]. While Chiolero et al. found that smoking can decrease energy intake by inhibiting appetite[30]. Smoking was associated with more participation in activity from this study. Similar to our results, Poortinga et al.[31] found a positive clustering between physical activity and smoking whereas other studies found negative associations[32, 33].Possible explanations include:(1) smoking is associated with different types of physical activity (2) Participants in this survey, aged between 18 and 65, were more likely to be involved in professional work activities. It may be 
that people with a manual occupation are more likely to smoke and to drink heavily, in addition to being more physically active due to the nature of their work, as compared to people with a non-manual occupation [34].Moreover, previous studies performed mostly among working-age people have shown smokers to be leaner than nonsmokers[35, 36].

In this longitudinal survey among Chinese adults, we found that current smokers had lower BMI than nonsmokers is consistent with many previous studies [37-39]. While the association between smoking and abdominal obesity yielded inconsistent findings. Xu et al. found male nonsmokers had non-significantly larger mean WC than current smokers[40]. In contrast, Mizuno et al. reported current smokers had a significant larger WC than nonsmoker just in obese male[41]. Liu et al. found nonsmokers had a larger WC than current smokers[42]. In the present study, after adjusting for potential confounders, we found that current smokers had a lower WC compared with nonsmokers regardless of gender. These contradictory findings show that the association still requires more attention.

\section{Smoking intensity and risk of obesity}

Moreover, the notable finding in the present study is that male who smoke equal to or more than 25 cigarettes per day increased the risk of the onset of general obesity and abdominal obesity compare to other smokers both independently and significantly. The heavy frequency of smoking was positively associated with BMI in male was in line with previous studies [43-45].Moreover, it is suggested that heavy smokers have a higher risk of obesity than light smokers among working-age people[46]. In our study, we find that heavy smoking increased dietary energy intake, physical inactivity and likelihood being drinking. After adjusting for these variables considerably change the estimated mean difference in BMI between heavy and other smokers. One possible explanation from Chiolero et al. is that heavy smokers also have behaviors favoring weight gain such as physical inactivity, unhealthy diet and high alcohol consumption[30].

Yet other studies have reported that WC increases with increasing pack years among current daily smokers [47, 48]. The amount smoked daily by smokers have also been reported to be positively associated with abdominal obesity [49]. Moreover, heavy smokers in the present study had a larger WC than other smokers. These findings were in accordance with several previous studies[50]. Several hypotheses might explain the association between heavy smoking and abdominal obesity in male. First, it has been reported that smoking affects fat distribution in the abdominal area by various biological mechanisms such as smoking affects the regulation of the sex hormones[30]. For example, firstly, lower levels of androgens in male current smokers has been found to increase abdominal obesity[51].Secondly, male heavy smokers are more likely to have unhealthy behaviors such as more calorie intake, increased alcohol use, which was also found in our study. These unhealthy behaviors may favor weight gain and partly explain the accumulation of visceral fat mass in abdominal area.

\section{Strengths and limitations}

First of strengths in this study was that we examined the association between smoking and risk of obesity by combine use smoking status and smoking intensity (based on the number of cigarette smoked in a day). Second, the longitudinal study design could confirmative evidence to causality. Third, we controlled several important sociodemographic and behavioral confounders and assess sex differences in estimated associations, which helped to improve the validity of our findings.

However, some limitations need to be mentioned. First, we were not able to control for former smokers' body weight status in smoke quitting period because of data usage restrictions that might lead to selection effect. Second, dietary data were collected using three consecutive 24-h dietary recalls, which might show relatively limited variations for a participant as compared to non-consecutive 24-h recalls.

\section{Conclusions}

Compared with nonsmokers, current smokers had lower probability of being general obesity and abdominal obesity among Chinese adults regardless of gender. Male heavy smokers significantly increased the risk of obesity than other smokers. These findings may improve the understanding on how smoking affects fat distribution and provide scientific evidence regarding intervention in smoking and obesity, especially for male heavy smokers.

\section{Abbreviations}


CHNS: China Health and Nutrition Survey; BMI: Body mass index; WC: Waist circumference; CDC: Centers for Disease Control and Prevention; MET: metabolic equivalents of task; WHO: World Health Organization; CDG: Chinese dietary guideline; DRI: Dietary Reference Intake; MET: Metabolic Equivalent of Task; PA: Physical Activity

\section{Declarations}

\section{Ethics approval and consent to participate}

The study was approved by the Institutional Review Boards of the University of North Carolina at Chapel Hill and the National Institute for Nutrition and Health, Chinese Center for Disease Control and Prevention. Each participant provided written informed consent (No. 201524).

\section{Consent for publication}

Not applicable

Availability of data and material

The datasets used and analysed during the current study are available from the corresponding author on reasonable request.

\section{Funding}

This work was supported by research grant from the Carolina Population Center (5 R24 HD 050924), University of North Carolina at Chapel Hill, the National Institutes of Health (NIH) (R01-HD30880, DK056350, and R01-HD38700) and the Fogarty International Center, $\mathrm{NIH}$ (5D43TW007709 and 5D43TW009077).

\section{Acknowledgement}

The authors thank the team at the National Institute for Nutrition and Health, Chinese Center for Disease Control and Prevention and the Carolina Population Center, University of North Carolina at Chapel Hill. The authors are also grateful to the participants for their involvement in the survey.

\section{Author's Contributions}

All authors contributed significantly to this article. JZ analyzed the data and wrote the manuscript, JS critically revised the manuscript for important intellectual content. All authors read and approved the final manuscript.

\section{Competing Interests}

The authors have no conflict of interest to declare

\section{Authors' Information}

1. Institute of Basic Medical Sciences, Chinese Academy of Medical Sciences / School of Basic Medicine, Peking Union Medical College, Beijing, China

2. School of Public Health \& Management, Ningxia Medical University, Chinese Center for Disease Control and Prevention, Ningxia 750004, China

\section{References}

1. Stokes A, Preston SH: How smoking affects the proportion of deaths attributable to obesity: assessing the role of relative risks and weight distributions. J Bmj Open 2016, 6:--

2. Prakash J, Mittal B, Apurva S, Shally A, Pranjal S, Neena S: Common Genetic Variant of insig2 Gene rs7566605 Polymorphism Is Associated with Severe Obesity in North India. Iranian Biomedical Journal 2017, 21:261-269.

3. Zhang H, Xu H, Song F, Xu W, Qi X: Relation of socioeconomic status to overweight and obesity: a large population-based study of Chinese adults. Annals of Human Biology 2017, 44:1-18. 
4. Pieroni L, Salmasi L: The effect of smoking habit changes on body weight: Evidence from the UK. Economics Human Biology 2016, 20:1-13.

5. Taylor AE, Richmond RC, Palviainen T, Loukola A, Wootton R, Kaprio J, Relton C, Smith GD, Munafò MR: The effect of body mass index on smoking behaviour and nicotine metabolism: a Mendelian randomization study. Human Molecular Genetics 2018.

6. Pasch KE, Velazquez CE, Cance JD, Moe SG, Lytle LA: Youth Substance Use and Body Composition: Does Risk in One Area Predict Risk in the Other? Journal of Youth \& Adolescence 2012, 41:14-26.

7. Tian J, Venn A, Otahal P, Gall S: The association between quitting smoking and weight gain: a systemic review and meta-analysis of prospective cohort studies. Obesity Reviews 2015, 16:883-901.

8. Istvan JA, CUNNINGHAM TW, GARFINKEL L: Cigarette Smoking and Body Weight in the Cancer Prevention Study I. International Journal of Epidemiology 1992, 21:849-853.

9. Eisen S, Lyons MJ, Goldberg J, True WR: The Impact of Cigarette and Alcohol Consumption on Weight and Obesity: An Analysis of 1911 Monozygotic Male Twin Pairs. Archives of Internal Medicine 1993, 153:2457-2463.

10. Shadrach D, F. MD, P. PJ, Keitaro M: Relationship between Smoking and Obesity: A Cross-Sectional Study of 499,504 Middle-Aged Adults in the UK General Population. Plos One 2015, 10:e0123579-.

11. Lv J, Chen W, Sun D, Li S, Millwood IY, Smith M, et a: Gender-Specific Association between Tobacco Smoking and Central Obesity among 0.5 Million Chinese People: The China Kadoorie Biobank Study. Plos One 2015, 10.

12. Sun HJ, Lee SY, Nam CM, Sang YK, Kim MT: Effect of Smoking on the Paradox of High Waist-to-Hip Ratio and Low Body Mass Index. Obesity 2002, 10:891-895.

13. Canoy D, Wareham N, Luben R, Welch A, Khaw KT: Cigarette Smoking and Fat Distribution in 21, 828 British Men and Women: A Population-based Study. Obesity (Silver Spring) 2005, 13:1466-1475.

14. Caks T, Kos M: Body shape, body size and cigarette smoking relationships. International Journal of Public Health 2009, 54:35-39.

15. De OFG, L., Neuberger M, Tichy A, Moshammer H: Cross-sectional association between cigarette smoking and abdominal obesity among Austrian bank employees. Bmj Open 2014, 4:e004899.

16. Onat A, Ayhan E, Hergen G, Can G, Barlan MM: Smoking inhibits visceral fat accumulation in Turkish women: Relation of visceral fat and body fat mass to atherogenic dyslipidemia, inflammatory markers, insulin resistance, and blood pressure. Metabolismclinical \& Experimental 2009, 58:963-970.

17. Sikorski C, Luppa M, Weyerer S, König HH, Riedel-Heller SG: Obesity and Associated Lifestyle in a Large Sample of Multi-Morbid German Primary Care Attendees. Plos One 2014, 9:e102587.

18. Wang, Qing: Smoking and body weight: evidence from China health and nutrition survey. Bmc Public Health 2015, 15:1238.

19. Perkins KA: Effects of tobacco smoking on caloric intake. British Journal of Addiction 2010, 87:193-205.

20. Poortinga WJPM: The prevalence of clustering of four major lifestyle risk factors in an English adult population. Prev Med 2007, 44:124-128.

21. Schuit AJ, van Loon AJ, Tijhuis M, Ocké M: Clustering of lifestyle risk factors in a general adult population. Prev Med 2002, 35:219224.

22. Marks BL, Perkins KA, Metz KF, Epstein LH, Robertson RJ, Goss FL, Disorders JESJIJoE: Effects of smoking status on content of caloric intake and energy expenditure. 10:441-449.

23. Wehby G L MJC, Wilcox A, et al. : Smoking and body weight: Evidence using genetic instruments. Economics \& Human Biology 2012, 10:0-126

24. Hu PJ, Ley SH, Bhupathiraju SN: Associations of dietary, lifestyle, and sociodemographic factors with iron status in Chinese adults a cross-sectional study in the China Health and Nutrition Survey. AM J CLIN NUTR 2017, 105:503-512.

25. Zhang J, Wang H, Wang Y, Xue H, Wang Z, Du W, Su C, Zhang J, Jiang H, Zhai F: Dietary patterns and their associations with childhood obesity in China. Br J Nutr 2015, 113:1978-1984.

26. Gao F, Wang ZJ, Shen H, Yang SW, Nie B, Zhou YJ: Impact of obesity on mortality in patients with diabetes: Meta-analysis of 20 studies including 250,016 patients. Journal of Diabetes Investigation 2017.

27. Chang WS, Won KH, Lee JY, Kim ET, Kweon HJ: The Relationship between Obesity and the High Probability of Dementia Based on the Body Mass Index and Waist Circumference. Korean Journal of Family Medicine 2012, 33:17-24. 
28. Huang L, Wang H, Wang Z, Zhang J, Zhang B, Ding G: Regional Disparities in the Association between Cereal Consumption and Metabolic Syndrome: Results from the China Health and Nutrition Survey. Nutrients 2019, 11:11.

29. Dallongeville J MN, Fruchart J C , et al.: Cigarette Smoking Is Associated with Unhealthy Patterns of Nutrient Intake: a Metaanalysis. Journal of Nutrition 1998, 128:1450-1457.

30. Chiolero A, Faeh D, Paccaud F, Cornuz J: Consequences of smoking for body weight, body fat distribution, and insulin resistance. Am J Clin Nutr 2008, 87:801-809.

31. Poortinga W: The prevalence of clustering of four major lifestyle risk factors in an English adult population. Prev Med 2007, 44:124-128.

32. Chiolero A, Wietlisbach V, Ruffieux C, Paccaud F, Cornuz J: Clustering of risk behaviors with cigarette consumption: A populationbased survey. Prev Med 2006, 42:348-353.

33. Kvaavik E, Meyer HE, Medicine ATJP: Food habits, physical activity and body mass index in relation to smoking status in 40-42 year old Norwegian women and men. Prev Med 2004, 38:0-5.

34. Poortinga W: Associations of physical activity with smoking and alcohol consumption: a sport or occupation effect? Prev Med 2007, 45:66-70.

35. Marti B, Tuomilehto J, Korhonen HJ, Kartovaara L, Vartiainen E, Pietinen P, Puska P: Smoking and leanness: evidence for change in Finland. BMJ 1989, 298:1287-1290.

36. Molarius A, Seidell JC, Kuulasmaa K, Dobson AJ, Sans S: Smoking and relative body weight: an international perspective from the WHO MONICA Project. Epidemiol Community Health 1997, 51:252-260.

37. Travier N AA, May AM, Gonzalez C, Luan J, Besson $\mathrm{H}$ et al: Smoking and body fatness measurements: A cross-sectional analysis in the EPIC-PANACEA study. Preventive Medicine 2009, 49:0-373.

38. Lee SA WW, Xu WH, Zheng W, Li H, Yang G et al: Prevalence of Obesity and Correlations With Lifestyle and Dietary Factors in Chinese Men Obesity (Silver Spring) 2008, 16:1440-1447.

39. Clair C, Chiolero A, Faeh D, Cornuz J, Vollenweider P: Dose-dependent positive association between cigarette smoking, abdominal obesity and body fat: Cross-sectional data from a population-based survey. Bmc Public Health 2011, 11:23.

40. Xu F, Yin XM, Wang YF: The Association between Amount of Cigarettes Smoked and Overweight, Central Obesity among Chinese adults in Nanjing, China. Asia Pacific Journal of Clinical Nutrition 2007, 16:240-247.

41. Mizuno O, Okamoto K, Sawada M, Mimura M, Watanabe T, Morishita T: Obesity and Smoking: Relationship with Waist Circumference and Obesity-Related Disorders in Men Undergoing a Health Screening. Journal of Atherosclerosis 2005, 12:199-204.

42. Liu L, Choudhury SR, Okayama A, Hayakawa T, Kita Y, Ueshima H: Changes in Body Mass Index and its Relationships to Other Cardiovascular Risk Factors among Japanese Population: Results from the 1980 and 1990 National Cardiovascular Surveys in Japan. Journal of Epidemiology 1999, 9:163-174.

43. Sulander T, Rahkonen $\mathrm{O}$, Nissinen A, Uutela A: Association of smoking status with obesity and diabetes among elderly people. Archives of Gerontology \& Geriatrics 2007, 45:159-167.

44. Chiolero A, Jacot SI, Faeh D,et al.: Association of Cigarettes Smoked Daily with Obesity in a General Adult Population. OBES REV 2007, 15:1311-1318.

45. John U, Hanke M, Rumpf HJ, Thyrian JR: Smoking status, cigarettes per day, and their relationship to overweight and obesity among former and current smokers in a national adult general population sample. Int J Obes (Lond) 2005, 29:1289-1294.

46. Patja K, JOUSILAHTI P, HU G, VALLE T, QIAO Q, TUOMILEHTO J: Effects of smoking, obesity and physical activity on the risk of type 2 diabetes in middle-aged Finnish men and women. Journal of Internal Medicine 2005, 258:356-362.

47. Hwan KJ, Won SK, Sook YY, Yeoup LS, Soo KS, Woo OS, Qi S: Cigarette Smoking Increases Abdominal and Visceral Obesity but Not Overall Fatness: An Observational Study. Plos One 2012, 7:e45815-.

48. Rom O, Karkabi K, Reznick AZ, Keidar Z, Aizenbud D: Relationship Between History of Smoking, Metabolic and Inflammatory Markers, Parameters of Body Composition and Muscle Strength. Advances in Experimental Medicine and Biology $2015,849$.

49. Fujiyoshi A, Miura K, Kadowaki S, Azuma K, Tanaka S, Hisamatsu T, Arima H, Kadota A, Miyagawa N, Takashima N: Lifetime cigarette smoking is associated with abdominal obesity in a community-based sample of Japanese men: The Shiga Epidemiological Study of Subclinical Atherosclerosis (SESSA). Preventive Medicine Reports 2016, 4:225-232.

50. Morris RW, Taylor AE, Fluharty ME: Heavier smoking may lead to a relative increase in waist circumference: evidence for a causal relationship from a Mendelian randomisation meta-analysis. BMJ Open 2015, 5:e008808. 

90:164-168.

\section{Tables}

\begin{tabular}{|c|c|c|c|}
\hline Variables & Total & Smoker & Non-smoker \\
\hline \multicolumn{4}{|c|}{ Demographic Characteristics } \\
\hline Age(year) & $42.98(12.70)$ & $43.58(12.17)$ & $42.72(12.92)^{* * *}$ \\
\hline Male & $0.48(0.50)$ & $0.95(0.23)$ & $0.28(0.45)^{* * *}$ \\
\hline \multicolumn{4}{|l|}{ Socioeconomic Status } \\
\hline \multicolumn{4}{|l|}{ Education level } \\
\hline Primary/illiterate & $0.38(0.49)$ & $0.36(0.48)$ & $0.38(0.49)^{* * *}$ \\
\hline Junior & $0.35(0.47)$ & $0.38(0.48)$ & $0.34(0.47)^{* * *}$ \\
\hline High school/above & $0.27(0.44)$ & $0.26(0.44)$ & $0.28(0.45)^{* * *}$ \\
\hline \multicolumn{4}{|l|}{ Income level } \\
\hline Low & $0.33(0.47)$ & $0.30(0.46)$ & $0.35(0.48)^{* * *}$ \\
\hline Medium & $0.34(0.47)$ & $0.32(0.47)$ & $0.35(0.48)^{* * *}$ \\
\hline High & $0.33(0.47)$ & $0.38(0.49)$ & $0.30(0.46)^{* * *}$ \\
\hline PA(METs/w) & $272.73(231.95)$ & $287.96(233.18)$ & $266.22(231.13)^{* * *}$ \\
\hline Married & $0.85(0.36)$ & $0.86(0.34)$ & $0.84(0.36)^{* * *}$ \\
\hline Employed & $0.72(0.45)$ & $0.81(0.39)$ & $0.68(0.47)^{* * *}$ \\
\hline Urban & $0.35(0.48)$ & $0.33(0.47)$ & $0.36(0.48)^{* * *}$ \\
\hline \multicolumn{4}{|l|}{ Dietary nutrition intake } \\
\hline Energy (1k kcal) & $2.28(0.96)$ & $2.48(1.09)$ & $2.19(0.88)^{* * *}$ \\
\hline Fat $(\mathrm{E} \%)^{4}$ & $30.12(13.00)$ & $29.70(13.42)$ & $30.30(12.81)^{* * *}$ \\
\hline \multicolumn{4}{|l|}{ Obesity indicators } \\
\hline $\mathrm{WC}(\mathrm{cm})$ & $80.66(10.59)$ & $81.73(10.30)$ & $80.21(10.68)^{* *}$ \\
\hline $\operatorname{BMI}\left(\mathrm{kg} / \mathrm{m}^{2}\right)$ & $23.04(3.44)$ & $22.77(3.22)$ & $23.16(3.52)^{* * *}$ \\
\hline General Obesity & $0.08(0.27)$ & $0.06(0.24)$ & $0.08(0.28)^{* * *}$ \\
\hline Abdominal Obesity & $0.39(0.49)$ & $0.35(0.48)$ & $0.41(0.49)^{* * *}$ \\
\hline \multicolumn{4}{|l|}{ Smoking intensity } \\
\hline Light $(1 \sim 14 / d)$ & l & $0.42(0.24)$ & l \\
\hline Moderate $(15 \sim 25 / d)$ & & $0.48(0.25)$ & 1 \\
\hline Heavy $(25+/ d)$ & 1 & $0.10(0.06)$ & 1 \\
\hline $\mathrm{N}$ & 75,348 & 22,541 & 52,807 \\
\hline
\end{tabular}

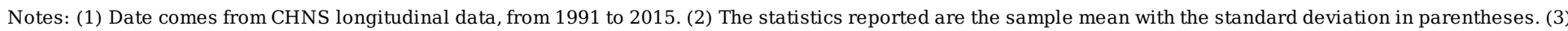
$* * *, * *$ and *indicates statistical significance at the $1 \% 5 \%$ and $10 \%$ level, respectively. (4) Fat (E \%) $\square$ percentage of energy intake from fat.

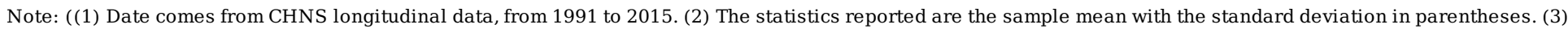
***, **and $*$ indicates statistical significance at the $1 \% 5 \%$ and $10 \%$ level, respectively. (4) Fat (E \%) $\square$ percentage of energy intake from fat.

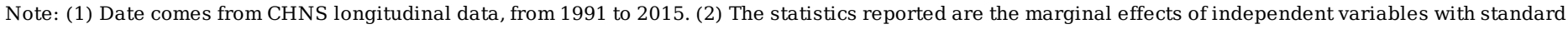

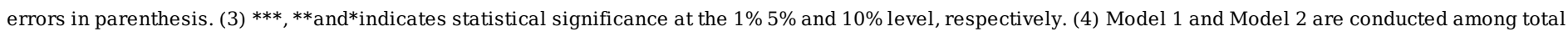

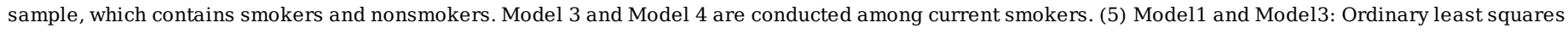

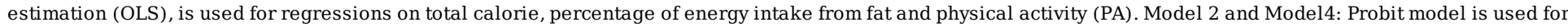

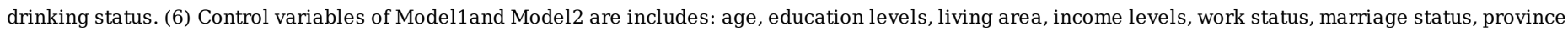
dummies and survey year dummies.

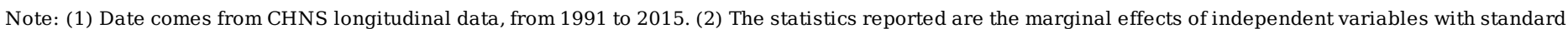

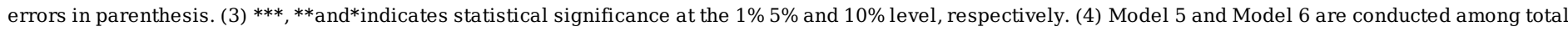

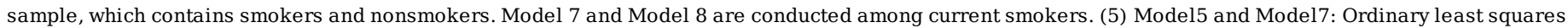

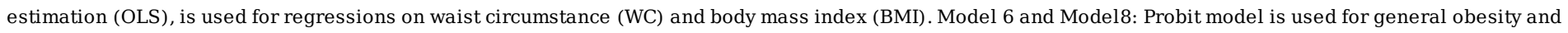

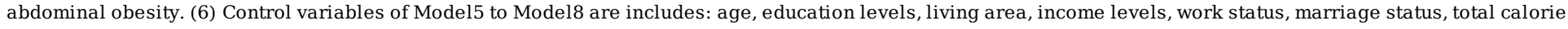
intake, percentage of energy intake from fat, physical activity(PA), drinking status, province dummies and survey year dummies. 
Table 2 Trends of characteristics among adult smokers from CHNS 1991 to $2015^{1-3}$

\begin{tabular}{|c|c|c|c|c|c|c|c|c|c|}
\hline Characteristic & 1991 & 1993 & 1997 & 2000 & 2004 & 2006 & 2009 & 2011 & 2015 \\
\hline Age (year) & $39.74(0.25)$ & $40.14(0.25)$ & $40.59(0.27)$ & $42.24(0.23)$ & $44.22(0.23)$ & $45.43(0.24)$ & $45.79(0.24)$ & $46.78(0.22)$ & $47.98(0.24)^{* * *}$ \\
\hline Male & $0.94(0.01)$ & $0.94(0.01)$ & $0.94(0.01)$ & $0.94(0.01)$ & $0.95(0.01)$ & $0.95(0.01)$ & $0.95(0.01)$ & $0.96(0.01)$ & $0.96(0.01)^{* * *}$ \\
\hline 1 14cigarettes/d & $0.45(0.01)$ & $0.42(0.01)$ & $0.39(0.01)$ & $0.41(0.01)$ & $0.41(0.01)$ & $0.39(0.01)$ & $0.38(0.01)$ & $0.38(0.01)$ & $0.39(0.01)^{* * *}$ \\
\hline $\begin{array}{l}15 \sim 24 \\
\text { cigarettes/d }\end{array}$ & $0.47(0.01)$ & $0.50(0.01)$ & $0.52(0.01)$ & $0.48(0.01)$ & $0.48(0.01)$ & $0.49(0.01)$ & $0.49(0.01)$ & $0.48(0.01)$ & $0.47(0.01)^{* * *}$ \\
\hline $25^{+}$cigarettes $/ \mathrm{d}$ & $0.08(0.01)$ & $0.08(0.01)$ & $0.09(0.01)$ & $0.11(0.01)$ & $0.11(0.01)$ & $0.12(0.01)$ & $0.13(0.01)$ & $0.14(0.01)$ & $0.14(0.01)^{* * *}$ \\
\hline Primary/illiterate & $0.55(0.01)$ & $0.49(0.01)$ & $0.47(0.01)$ & $0.41(0.01)$ & $0.36(0.01)$ & $0.33(0.01)$ & $0.28(0.01)$ & $0.20(0.01)$ & $0.11(0.01)^{* * *}$ \\
\hline Junior & $0.29(0.01)$ & $0.34(0.01)$ & $0.33(0.01)$ & $0.36(0.01)$ & $0.39(0.01)$ & $0.40(0.01)$ & $0.44(0.01)$ & $0.42(0.01)$ & $0.39(0.01)^{* * *}$ \\
\hline $\begin{array}{l}\text { High } \\
\text { school/above }\end{array}$ & $0.16(0.01)$ & $0.16(0.01)$ & $0.19(0.01)$ & $0.22(0.01)$ & $0.24(0.01)$ & $0.27(0.01)$ & $0.28(0.01)$ & $0.37(0.01)$ & $0.43(0.01)^{* * *}$ \\
\hline Income(Low) & $0.34(0.01)$ & $0.31(0.01)$ & $0.31(0.01)$ & $0.30(0.01)$ & $0.26(0.01)$ & $0.25(0.01)$ & $0.30(0.01)$ & $0.28(0.01)$ & $0.31(0.01)^{* * *}$ \\
\hline Income (Medium) & $0.24(0.01)$ & $0.31(0.01)$ & $0.29(0.01)$ & $0.35(0.01)$ & $0.36(0.01)$ & $0.37(0.01)$ & $0.34(0.01)$ & $0.34(0.01)$ & $0.30(0.01)^{* * *}$ \\
\hline Income (High) & $0.42(0.01)$ & $0.38(0.01)$ & $0.40(0.01)$ & $0.35(0.01)$ & $0.38(0.01)$ & $0.38(0.01)$ & $0.36(0.01)$ & $0.38(0.01)$ & $0.39(0.01)^{* * *}$ \\
\hline Married & $0.84(0.01)$ & $0.84(0.01)$ & $0.83(0.01)$ & $0.85(0.01)$ & $0.86(0.01)$ & $0.89(0.01)$ & $0.88(0.01)$ & $0.89(0.01)$ & $0.90(0.01)^{* * *}$ \\
\hline Employed & $0.89(0.01)$ & $0.89(0.01)$ & $0.89(0.01)$ & $0.84(0.01)$ & $0.76(0.01)$ & $0.75(0.01)$ & $0.77(0.01)$ & $0.78(0.01)$ & $0.67(0.01)^{* * *}$ \\
\hline Drinking & $0.73(0.01)$ & $0.69(0.01)$ & $0.72(0.01)$ & $0.70(0.01)$ & $0.68(0.01)$ & $0.69(0.01)$ & $0.69(0.01)$ & $0.71(0.01)$ & $0.68(0.01)^{* * *}$ \\
\hline Urban & $0.31(0.01)$ & $0.30(0.01)$ & $0.32(0.01)$ & $0.32(0.01)$ & $0.33(0.01)$ & $0.34(0.01)$ & $0.33(0.01)$ & $0.39(0.01)$ & $0.35(0.01)^{* * *}$ \\
\hline Energy (1k kcal) & $2.89(0.01)$ & $2.77(0.01)$ & $2.57(0.01)$ & $2.48(0.01)$ & $2.42(0.01)$ & $2.41(0.01)$ & $2.40(0.01)$ & $2.18(0.01)$ & $2.24(0.02)^{* * *}$ \\
\hline Fat $(\% E)^{4}$ & $25.93(0.25)$ & $25.48(0.26)$ & $25.89(0.24)$ & $28.44(0.22)$ & $26.88(0.26)$ & $30.95(0.34)$ & $31.33(0.23)$ & $35.91(0.24)$ & $36.72(0.26)^{* * *}$ \\
\hline $\begin{array}{l}\text { Carbohydrates(\%E } \\
\text { ) }\end{array}$ & $60.08(0.28)$ & $60.09(0.29)$ & $61.12(0.25)$ & $58.31(0.25)$ & $59.13(0.27)$ & $53.94(0.28)$ & $52.63(0.25)$ & $49.55(0.24)$ & $48.84(0.26)^{* * *}$ \\
\hline $\mathrm{PA}(\mathrm{METs} / \mathrm{w})$ & $396.72(4.67)$ & $342.93(4.45)$ & $364.04(4.54)$ & $301.35(4.30)$ & $261.93(4.75)$ & $262.38(5.18)$ & $248.12(4.66)$ & $235.34(3.86)$ & $158.93(3.45)^{* * *}$ \\
\hline
\end{tabular}

Table 3 Effects of smoking behavior on risk of Obesity ${ }^{1-6}$

\begin{tabular}{|c|c|c|c|c|c|c|c|c|}
\hline & \multicolumn{4}{|l|}{ Female } & \multicolumn{4}{|l|}{ Male } \\
\hline & $\begin{array}{l}\text { Total calorie } \\
(\text { Kcal) }\end{array}$ & $\begin{array}{l}\text { Fat } \\
(\% \mathrm{E})\end{array}$ & $\begin{array}{l}\text { PA } \\
(\mathrm{METs} / \mathrm{w})\end{array}$ & Drinking & $\begin{array}{l}\text { Total calorie } \\
\text { (Kcal) }\end{array}$ & $\begin{array}{l}\text { Fat } \\
(\% \mathrm{E})\end{array}$ & $\begin{array}{l}\text { PA } \\
(\mathrm{METs} / \mathrm{w})\end{array}$ & Drinking \\
\hline \multicolumn{9}{|c|}{ Marginal effects of smoking status $(\mathrm{N}=75,348)$} \\
\hline Model 1 & $-29.57(29.07)$ & $0.60(0.34)^{*}$ & $10.07(6.17)$ & & $23.28(11.32)^{* *}$ & $0.47(0.13)^{* * *}$ & $9.96(2.02)^{* * *}$ & \\
\hline Model 2 & & & & $0.79(0.04)^{* *}$ & & & & $0.61(0.01)^{* * *}$ \\
\hline \multicolumn{9}{|c|}{ Marginal effects of number of cigarettes consumed daily ( current smoker $\square=22,541$ ) } \\
\hline Model 3 & $3.20(3.91)^{* * *}$ & $-1.35(0.72)^{*}$ & $7.35(128)$ & & $-81.23(13.80)^{* * *}$ & $-0.59(0.17)^{* * *}$ & $-7.80(2.72)^{* * *}$ & \\
\hline Model 4 & & & & $-0.27(0.09)^{* * *}$ & & & & $-0.02(0.02)$ \\
\hline \multicolumn{9}{|c|}{ Moderate smoker(15 25 /d) } \\
\hline Model 3 & $6.36(3.87)^{* * *}$ & $1.62(0.75)^{* *}$ & $-2.23(1.31)$ & & $43.44(14.24)^{* * *}$ & $0.51(0.17)^{* * *}$ & $1.75(2.66)$ & \\
\hline Model 4 & & & & $0.26(0.09)^{* * *}$ & & & & $-0.01(0.02)$ \\
\hline \multicolumn{9}{|c|}{ Heavy smoker(25+/d) } \\
\hline Model 3 & $-6.57(9.05)$ & $-1.25(1.56)$ & $-2.24(1.31)$ & & $89.65(19.76)^{* * *}$ & $0.13(0.29)$ & $15.31(4.68)^{* * *}$ & \\
\hline Model 4 & & & & $0.18(0.23)$ & & & & $0.08(0.03)^{* * *}$ \\
\hline
\end{tabular}

Table 4 Effects of smoking behavior on risk of being General obesity and Abdominal obesity ${ }^{1-6}$

\begin{tabular}{|c|c|c|c|c|c|c|c|c|}
\hline & \multicolumn{4}{|l|}{ Female } & \multicolumn{4}{|l|}{ Male } \\
\hline & $\mathrm{WC}(\mathrm{cm})$ & BMI $\left(\mathrm{kg} / \mathrm{m}^{2}\right)$ & General Obesity & Abdominal Obesity & WC (cm) & BMI $\left(\mathrm{kg} / \mathrm{m}^{2}\right)$ & General Obesity & Abdominal Obesity \\
\hline \multicolumn{9}{|c|}{ Marginal effects of smoking status $(\mathrm{N}=75,348)$} \\
\hline Model 5 & $-1.35(0.35)^{* * *}$ & $-0.60(0.11)^{* * *}$ & & & $-0.87(0.11)^{* * *}$ & $-0.46(0.03)^{* * *}$ & & \\
\hline Model 6 & & & $-0.03(0.05)^{* * *}$ & $-0.12(0.01)^{* * *}$ & & & $-0.17(0.02)^{* * *}$ & $-0.12(0.02)^{* * *}$ \\
\hline \multicolumn{9}{|c|}{ Marginal effects of number of cigarettes consumed daily (current smoker $n=22,541$ ) } \\
\hline \multicolumn{9}{|c|}{ Light smoker(1 14 /d) } \\
\hline Model 7 & $0.13(0.76)$ & $0.02(0.24)$ & & & $0.07(0.04)^{*}$ & $-0.11(0.14)$ & & \\
\hline Model 8 & & & $0.13(0.11)$ & $0.01(0.09)$ & & & $-0.02(0.03)$ & $-0.01(0.02)$ \\
\hline \multicolumn{9}{|c|}{ Moderate smoker(15 25/d) } \\
\hline Model 7 & $-0.34(0.80)$ & $-0.01(0.24)$ & & & $-0.15(0.14)^{* * *}$ & $-0.20(0.14)$ & & \\
\hline Model 8 & & & $-0.13(0.11)$ & $-0.04(0.09)$ & & & $-0.05(0.03)^{* *}$ & $-0.03(0.02)$ \\
\hline \multicolumn{9}{|c|}{ Heavy smoker $(25+/ d)$} \\
\hline Model 7 & $1.33(1.64)$ & $0.10(0.57)$ & & & $0.81(0.22)^{* * *}$ & $0.23(0.07)^{* * *}$ & & \\
\hline Model 8 & & & $0.03(0.32)$ & $0.19(0.24)$ & & & $0.18(0.05)^{* * *}$ & $0.10(0.03)^{* * *}$ \\
\hline
\end{tabular}




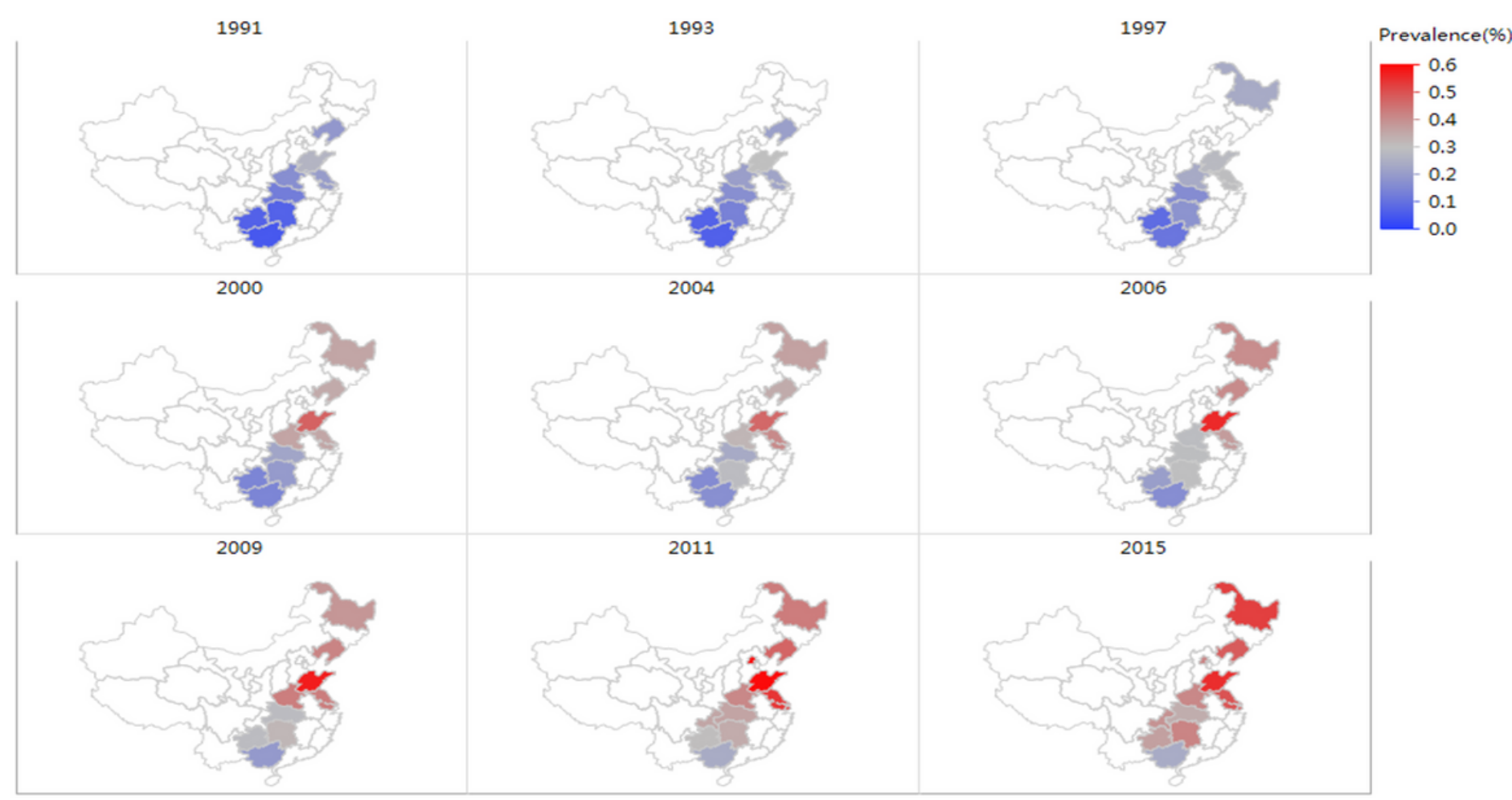

\section{Figure 1}

Shift in distribution of prevalence of overweight and obesity in current smokers among Chinese adults from CHNS1991 to 2015 . Note: The map includes provinces in mainland China but excludes Taiwan, Hong Kong and Macau. Note: The designations employed and the presentation of the material on this map do not imply the expression of any opinion whatsoever on the part of Research Square concerning the legal status of any country, territory, city or area or of its authorities, or concerning the delimitation of its frontiers or boundaries. This map has been provided by the authors.

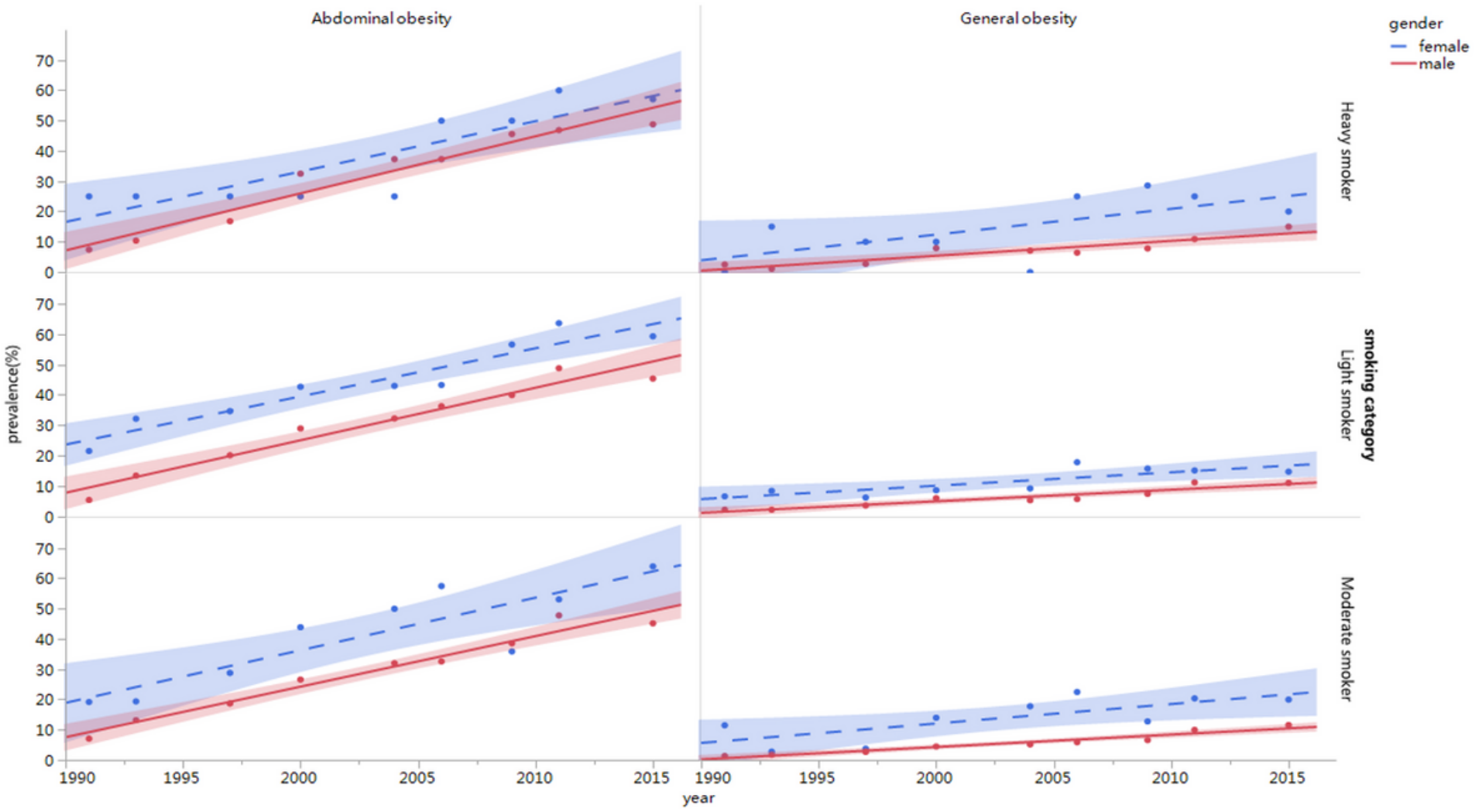

Page $11 / 12$ 
Figure 2

Trends of general obesity and abdominal obesity in Chinese adults by smoking intensity from CHNS1991 to 2015 